IFN Working Paper No. 841, 2010

\title{
Does the Debt Tax Shield Distort Ownership Efficiency?
}

Pehr-Johan Norbäck, Lars Persson and Joacim Tåg 


\title{
Does the Debt Tax Shield Distort Ownership Efficiency?*
}

\author{
Pehr-Johan Norbäck \\ Research Institute of Industrial Economics (IFN) \\ Lars Persson \\ Research Institute of Industrial Economics (IFN) and CEPR \\ Joacim Tåg \\ Research Institute of Industrial Economics (IFN)
}

September 2017

\begin{abstract}
The tax laws of most developed countries are debt biased since firms can deduct interest on debt but not on equity. This bias is known to distort investment decisions. However, less is known about how the debt tax shield affects the ownership of assets when bidders differ financial expertise and thus in optimal use of leverage. We show that the debt tax shield need not always distort ownership efficiency. Assets end up with the socially preferred owner when differences in financial and productive expertise between bidders is small and better financial expertise reduces expected bankruptcy costs.
\end{abstract}

Keywords: Acquisitions, Capital Gains Tax, Corporate Tax, LBOs, M\&As, Ownership, Private Equity, Tax Shields.

JEL Codes: D20, G32, G33, G34, H25, H32, L19, L22.

*We thank Sylvain Bourjade, Andreas Haufler, Fausto Panunzi, Roger Gordon, Luigi Guiso, Magnus Henrekson, Christian Keuschnigg, Mikko Mustonen, Gordon Phillips, and participants at the FDPE Workshop in Helsinki, SIFR and IFN in Stockholm, 9th Journées Louis-André Gérard-Varet Conference in Public Economics in Marseille, The EARIE Conference in Rome and at Copenhagen University for great comments and suggestions. Financial support from Tom Hedelius' and Jan Wallander's Research Foundations, the Marianne and Marcus Wallenberg Foundation, and the NASDAQ OMX Nordic Foundation is gratefully acknowledged. E-mail: pehr-johan.norback@ifn.se (Norbäck), lars.persson@ifn.se (Persson), and joacim.tag@ifn.se (Tåg). Corresponding author: Lars Persson, Research Institute of Industrial Economics, Box 55665, SE-102 15 Stockholm, Sweden. Phone: +468665 4500. Fax: +4686654599. 


\section{Introduction}

The tax laws of most developed countries are debt biased in that firms can deduct interest expenses on debt but not on equity. This bias is known to distort corporate investment decisions. As a subsidy for debt financing, the economic implications are large. Kemsley and Nissim (2002) estimate the value of the debt tax shield to equal roughly $10 \%$ of firm value. In this paper we examine how this debt bias affects the allocation of assets in mergers and acquisitions. We ask under what conditions the preferred owner from a welfare perspective obtains the corporate assets in the presence of a debt tax shield. Given the very high activity in the market for corporate control in most developed countries, potential inefficiencies in this market due to the debt bias could have substantial negative welfare costs.

Our central finding is that the debt tax shield does not always distort ownership efficiency. Assets end up with the socially preferred owner when differences in financial expertise between bidders is small or when the difference is large but better financial expertise reduces expected bankruptcy costs. We also point out that the debt tax shield can lead to lower consumer surplus irrespectively of ownership efficiency.

To reach this conclusion, we in section 2 of the paper develop a model of endogenous ownership of corporate assets and endogenous leverage choice. The model combines an endogenous acquisition model along the lines of Norbäck and Persson (2009) with a standard corporate finance trade-off theory model for capital structure choice. ${ }^{1}$ In the model, a firm called the target has assets needed for production in a monopoly industry. In stage one, the target's assets are up for sale through a first price perfect information auction. The bidders in this auction are firms of type $i$ or $p$ who are not currently present in the industry. Firm differ in that they can have different combinations of productivity and financial expertise. We capture financial expertise by lower real bankruptcy costs in case of default. Such lower costs can arise because these firms are multinational or multi-product firms, which allows them to diversify bankruptcy risk, or because they are better than other firms at handling the event of a bankruptcy. ${ }^{2}$ In stage two, after the assets have been sold, the owner decides on the leverage of the firm. In stage three, product market profits are realized, debts are repaid, product market actions are set, and tax payments are made. ${ }^{3}$ Tax payments consist of corporate (or profit) taxes net of deductions in case the firm does not default.

What are the merits of this specific setup? First, our model allows for companies to endogenously choose how much leverage to use. They do this to balance the gains from the debt tax shield with the costs of bankruptcy. Second, our model contains an auction that generates an equilibrium ownership of asset which take into account how the debt tax shield affects the value of the assets being sold. This is crucial for examining how the debt tax shield affects the equilibrium ownership of assets. Third, our modeling setup includes the product market. Thus, we can make statements about the effects on consumer surplus due to the effects of the debt tax shield on the allocation of assets in mergers and acquisitions. This is important since mergers and acquisitions often takes place in concentrated markets where firms have considerable market power.

\footnotetext{
${ }^{1}$ See, for example, Bradley, Jarrell, and Kim (1983).

${ }^{2}$ One example of a category of bidders for corporate assets that typically use high leverage are private equity firms. Empirical evidence shows that private equity backed firms have higher leverage than other firms (Axelson, Jenkinson, Strömberg, and Weisbach, 2013) and face lower marginal tax rates as a result of the debt tax shield (Badertscher, Katz, and Olhoft Rego, 2009). Moreover, Jenkinson and Stucke (2011) document a robust relationship between tax savings and the size of takeover premia, while Kaplan (1989) shows that interest deductibility benefits amount to up to $21 \%$ of the premium paid. A plausible reason for higher leverage in private equity backed firms is that private equity firms face lower real costs of bankruptcy: Hotchkiss, Smith, and Strömberg (2011) show that private equity backed firms tend to emerge from bankruptcy quicker than other types of firms. Moreover, private equity firms repeatedly interact with banks to finance acquisitions across multiple markets. Therefore, they have incentives to specialize in restructuring and in dealing with banks in the case of financial distress because they can spread the costs of specialization across many markets (Norbäck, Persson, and Tåg, 2013).

${ }^{3}$ Conflicts of interest between debt-holders and equity-holders are not present and random fixed costs are realized before product market actions are determined. Hence, the optimal leverage choice will not affect product market actions and profits because of equity-debtholder conflicts as in Brander and Lewis (1986) or because of the presence of bankruptcy costs as in Brander and Lewis (1988).
} 
In section 3 we derive the conditions under which the debt tax shield does not distort ownership efficiency. First, we show that if both potential owners are similar in financial expertise but differ in productivity then the debt tax shield will not distort ownership efficiency. The market will allocate the assets to the owner that makes the highest productive use of the assets even in the presence of a debt tax shield and this is also the owner that is preferred from a total welfare perspective.

Second, we show that if both potential owners can make equally productive use of the assets but they differ in financial expertise, the market will allocate the assets to the correct owner from a total welfare perspective only if financial expertise leads to lower expected bankruptcy costs. Intuitively, firms use leverage to minimize the tax burden by balancing the benefits of tax savings from the debt tax shield with the costs in case of bankruptcy. Tax payments are simply transfers between agents, so only expected bankruptcy costs have an effect on total welfare. Thus, firms with high financial expertise may choose to increase leverage so much that expected bankruptcy costs increase despite that they have lower real bankruptcy costs. They are willing to increase expected bankruptcy costs because of the tax savings of leverage. Thus, when we are in a situation in which financial expertise lowers expected bankruptcy costs and productivity differences between owner types are small, the debt tax shield does not distort ownership efficiency.

Finally, we also show that when the market allocates the target to an owner with relatively higher financial expertise but relatively lower productivity we can, under some conditions, have two negative effects on expected welfare from a debt tax shield. First, expected welfare can decline as expected bankruptcy costs increase due to higher leverage. Second, expected welfare can decline because productivity is reduced as the owner with the lower productivity obtains the assets (also lowering expected consumer surplus).

Our paper contributions to two strands of literature. First, our paper relates to the literature on taxation and ownership efficiency, which has proposed the concept of Capital Ownership Neutrality. In informal work, Desai and Hines (2004) argues that in a perfect competition framework with ownership asymmetries, tax rules should be set up such that assets end up with the buyer who has the highest reservation price in the absence of tax differences (see also Devereux (2008)). This concept has been formalized in various setting by, among others, Becker and Fuest (2009), Norbäck, Persson, and Vlachos (2009), Becker and Fuest (2010), Schindler and Schjelderup (2012), and Haufler and Runkel (2012). Our paper contributes by detailing the conditions under which Capital Ownership Neutrality holds with respect to the allocation of assets in mergers and acquisitions in the presence of a debt tax shield. ${ }^{4}$

Second, by building on the trade-off theory model for capital structure choice and casting it in a mergers and acquisitions setting our model relates to the finance literature on the tax benefits of debt. Models of how capital structure decisions interact with the optimal scope of the firm are related, but these do not typically consider efficiency from a total welfare perspective. ${ }^{5} \mathrm{~A}$ finance literature that does look at the total welfare effects of leverage exists (see, e.g. Kiyotaki and Moore (1997), Shleifer and Vishny (1992), He and Matvos (2012), Almazan, de Motta, and Titman (2012) and the survey in de Mooij (2011)), but this literature has not studied leverage and asset allocations in mergers and acquisitions. Our paper does this and thus contributes by presenting conditions under which leverage can affect total welfare through mergers and acquisitions.

\footnotetext{
${ }^{4}$ In relation to Becker and Fuest (2010), Becker and Fuest (2009), Haufler and Runkel (2012) and Schindler and Schjelderup (2012), our model explicitly accounts for how buyers' valuations of target firms depend on the debt tax shield and firms' optimal leverage decisions. And by studying endogenous ownership, our approach explicitly allows for firms to be acquired through competitive auctions. In contrast to Norbäck et al. (2009) we allow for deductions related to the debt tax shield and we explicitly model optimal leverage using a trade-off theory model from the finance literature. There is also a related literature on cross-border acquisitions and taxes that abstracts from the ownership efficiency asymmetries and tax shields of debt, see, for example, Gordon and Bovenberg (1996), Haufler and Schulte (2007), Egger, Eggert, Keuschnigg, and Winner (2010), and Becker and Fuest (2011)

${ }^{5}$ See Leland (2007) or the surveys in Myers (1990), Graham (2006). That is also the case of models that study how financial structures affects product markets. See, for example, Brander and Lewis (1986), Cestone and Fumagalli (2005), Banal-Estanol and Ottaviani (2006), and Chang, Chen, Chou, and Huang (2015).
} 

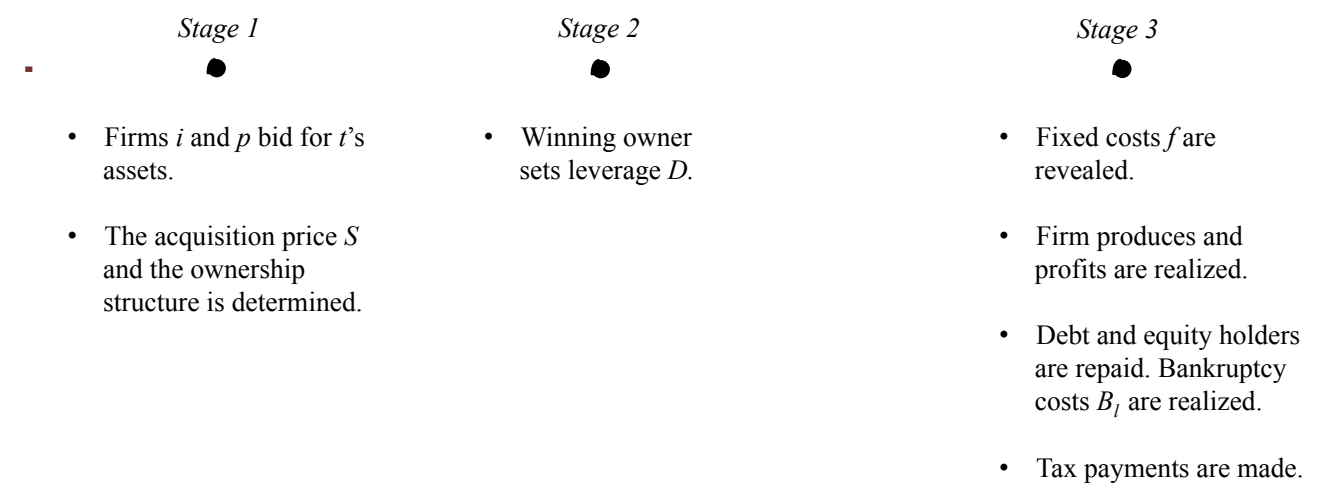

Figure 1: The timing of the game we analyze.

\section{The Model}

We begin with setting up and solving the model, showing how endogenous leverage choices in the presence of a debt tax shield feed back into the equilibrium ownership structure determined in the acquisition auction.

\subsection{Setup}

The timing of the game is described in Figure 1. A firm called the target, $t$, has assets needed for production in a monopoly industry. In stage one, $t$ 's assets are up for sale through a first price perfect information auction. The bidders in this auction are firms of type $i$ or $p$ who are not currently present in the industry. The productivity parameter $\gamma_{l}>0$ correspond to how efficiently an owner $l \in\{i, p\}$ can use $t$ 's assets to produce output in the product market. Firms also differ in their financial expertise, that is, in how well they can handle financial distress. We capture this through the parameter $B_{l}$ which measures the real bankruptcy costs incurred if the firm defaults on debt payments. The bankruptcy costs captures the long and complicated bankruptcy process that imposes costs on the firm and its investors. There are both direct and indirect costs. The direct costs include administrative and court cost, legal and advisory fees, time and resources spent by management and creditors dealing with bankruptcy, and mismanagement by judges (blocking/delaying non-routine expenditures). The indirect costs include loss of intangible assets (brand name and reputation), loss of customer confidence, key employees and suppliers, and fire sales of assets. Our model is meant to capture that firms bidding for assets up for sale may differ substantially in the magnitude of these costs related to financial distress $\left(B_{l}\right)$, but that they also differ substantially in how productively they can make use of the assets they acquire $\left(\gamma_{l}\right)$.

The set of bidders in the auction is $\mathcal{J}=\left\{i_{1}, i_{2}, . ., i_{n}, p_{1}, p_{2}, . ., p_{m}\right\}$, where the first $n \geq 2$ entries refer to the $n$ number of symmetric $i$ :s and the final $m \geq 2$ entries to the $m$ number of symmetric $p$ :s. The set of potential owners of $t$ 's assets are $\mathcal{L}=\mathcal{J}$, where $l \in \mathcal{L}$ is an element. The winner in the auction, $l$, pays an acquisition price of $S$ and obtains $t$ 's assets (and can thus produce in stage three).

In stage two, the owner $l$ decides on debt by setting $D$, which is a (fully deductible) debt repayment that must be made in stage three. ${ }^{6}$ The owner of the firm uses debt for tax planing purposes and trades off the tax benefits of leverage with expected bankruptcy costs in case of default. Financial markets are competitive, the risk free interest rate is zero, and debt contracts cannot be renegotiated.

In stage three, product market actions $x$ are determined, profits are realized, debts are repaid, and tax payments are made. At this stage, firm also faces a (deductible) fixed cost of $f$ with $H(f) \in\left[0, f^{\max }\right]$ and the probability density function $h(f)$. Events unfold as follows in this stage.

\footnotetext{
1976).

${ }^{6}$ We assume away any conflicts of interest between debt-holders and equity holders (Jensen and Meckling,
} 
First, the fixed cost $f$ is revealed. Then product market actions are determined, fixed costs paid, and profits realized. ${ }^{7}$ Second, debt repayments $D$ are made. If debt repayments exceed product market profits net of fixed costs, the firm defaults and incurs a real fixed bankruptcy cost of $B_{l}$. For simplicity, $t$ 's owners pay no taxes on the acquisition price and no capital gains or dividend taxes are paid by owner $l$. The only tax payments made are thus corporate (or profit) taxes net of deductions in case the firm does not default.

In what follows, we solve this game through backwards induction.

\subsection{Stage 3: The Product Market}

Events in this stage unfold as follows. First, the fixed cost $f$ is revealed. Second, product market actions are determined, fixed costs paid, and profits realized. Finally, debt repayments $D$ are made. If debt repayments are lower than product market profits net of fixed costs, $\pi(x, l)-f>D$, the firm pays a tax payment $\tau(\pi(x, l)-f-D)$. If debt repayments exceed product market profits net of fixed costs, $\pi(x, l)-f<D$, the firm defaults and incurs a real fixed bankruptcy cost of $B_{l}$. Finally, the firm decides whether to produce or not ( $f$ needs to be paid only if production generates net positive value) and on what the optimal output is. We first analyze product market actions under no default, then product market actions in case the firm defaults.

No default. This occurs when the realization of operating fixed cost is $f \in[0, \pi(x, l)-D)$. This gives equity value $E(x, D, l)=(1-\tau)[\pi(x, l)-f-D]$ and a debt value of $D$. Thus the value of the firm is

$$
\begin{aligned}
V(x, D, l) & =E(x, D, l)+D \\
& =(1-\tau)[\pi(x, l)-f]+\tau D .
\end{aligned}
$$

The optimal action, which could be setting a price or a quantity, is then given from the condition

$$
\pi\left(x^{*}, l\right) \geq \pi(x, l) .
$$

Taxes do not appear in this expression, so they do not distort the optimal product market action, which we assume to be strictly positive $x^{*}(l)>0$. From (2), we can define $\pi(l)=\pi\left(x^{*}(l), l\right)$ as the reduced-form product market profit and $V(D, l)=(1-\tau)[\pi(l)-f]+\tau D$ as the reduced-form value of the firm.

Default. Default occurs when the realization of operating fixed cost is $f \in\left[\pi(x, l)-D, f^{\max }\right]$. This gives an equity value of $E=0$ and a debt value of $D(x, l)=\pi(x, l)-f-B_{l}<D$. The value of the firm is thus

$$
V(x, l)=\pi(x, l)-f-B_{l} .
$$

It follows that the optimal product market action $x^{*}(l)$ is still given from (2). The firm will not supply the good if the reduced-form profit $\pi(l)=\pi\left(x^{*}(l), l\right)$ at $x^{*}(l)>0$ is smaller than the operating fixed cost, $f$. If this happens, the firm only pays the bankruptcy cost, $B_{l}$, but does not supply the good, $x^{*}(l)=0$. The real bankruptcy costs $B_{l}$ has to be paid even if the firm does not produce, since promised debt payments $D$ cannot be repaid without any profits.

The above two paragraphs allow us to state the value of the firm as a function of leverage $D$ and ownership $l$ for the various outcomes of the fixed cost $f$ :

$$
V(D, l)=\left\{\begin{array}{l}
(1-\tau)[\pi(l)-f]+\tau D, \text { for } f \in[0, \pi(l)-D) \\
\pi(l)-f-B_{l}, \text { for } f \in[\pi(l)-D, \pi(l)) . \\
-B_{l}, \text { for } f \in\left[\pi(l), f^{\max }\right)
\end{array}\right.
$$

\footnotetext{
${ }^{7}$ To keep the setup simple, fixed costs are realized before product market actions are determined. If product market actions are set before $f$ is realized, they will depend on taxes and debt levels. However, due to the envelope theorem, the optimal debt level and acquisition price will not be affected.
} 


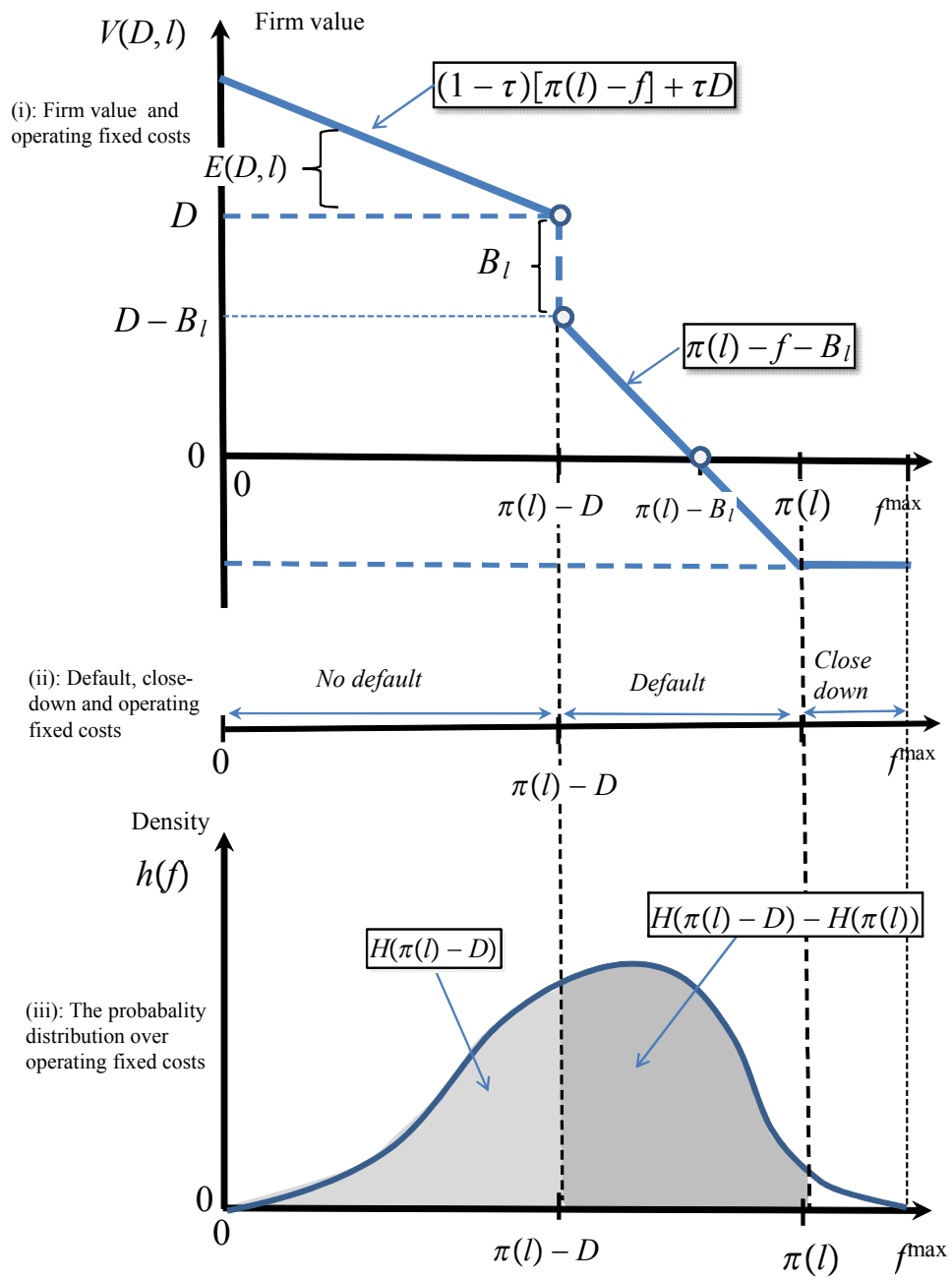

Figure 4: Part (i) of the figure displays the value of the firm at various fixed cost realizations.

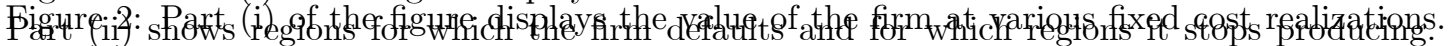

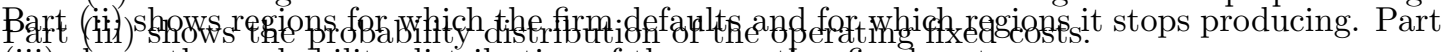
(iii) shows the probability distribution of the operating fixed costs.

This expression is illustrated in Figure 2(i). The first segment shows the equity and debt value of the firm when the realized fixed cost value is so low that no default occurs. When realized fixed cost becomes so high that $\pi(l)-f<D$, default occurs and the bankruptcy cost $B_{l}$ is incurred. Therefore the value of the firm curve jumps down to $\pi(l)-f-B_{l}$. No taxes are paid in this interval since debt payments are tax deductible. Since $\pi(l)-f>0$, the firm will continue to produce even though $\pi(l)-f-B_{l}<0$. At higher realized fixed cost $\pi(l)-f>0$, the firm will stop producing (setting $x^{*}(l)=0$ ) and then only incur the bankruptcy cost $B_{l}$.

For later use, let us now also specify in detail how productivity $\gamma$ affects product market profits and consumer surplus.

12

Assumption 1 Increased productivity $\gamma$ leads to higher product market profits $d \pi(l) / d \gamma_{l}>0$ and higher consumer surplus $\partial C S(l) / \partial \gamma>0$, with $C S(l)=C S\left(x^{*}(l)\right)$.

Consumer surplus is increasing in productivity $\gamma$ as a more efficient owner will quote lower prices $(\partial C S(l) / \partial \gamma>0)$. Assuming simple monopoly pricing, increasing efficiency will also increase the sum of consumer surplus and product market profits since consumers will benefit from higher efficiency through lower prices.

Example 1 Assume that the inverse demand is linear, $P_{l}=a-x_{l}$, and that production of a 
unit of the good requires $1 / \gamma_{l}$ bundles of inputs where the cost of a bundle is $c . \gamma_{l}$ is then the productivity of a firm of type $l$. With a marginal cost of $c_{l}=c / \gamma_{l}$ the reduced-form product market profit is $\pi(l)=\left[x^{*}(l)\right]^{2}>C S(l)=(1 / 2) \pi(l)$, where $x^{*}(l)=(1 / 2)\left[a-c / \gamma_{l}\right]$. The consumer surplus does not depend on leverage since the firm will produce the good as long as $\pi(l)>f$. Thus, $C S(l)>0$ holds for $\pi(l)>f$, whereas $C S(l)=0$ holds for $\pi(l)<f$ since the action $x^{*}(l)=0$ associated with close down implies that the good or service is not produced.

\subsection{Stage 2: Leverage Choice}

In stage two, the debt level of the firm $D$ is set by owner $l$ to maximize the expected firm value $\bar{V}(l, D): D^{*}(l)=\arg \max _{D} \bar{V}(l, D)$. Suppose first that the leverage chosen is strictly positive $\left(D^{*}(l)>0\right)$. Making use of equation (4), the value of the firm is

$$
\begin{gathered}
\bar{V}(D, l)=\int_{0}^{\pi(l)-D}\{(1-\tau)[\pi(l)-f]+\tau D\} h(f) d f+ \\
\int_{\pi(l)-D}^{\pi(l)}\left\{\pi(l)-f-B_{l}\right\} h(f) d f-\int_{\pi(l)}^{f^{\max }} B_{l} h(f) d f .
\end{gathered}
$$

As illustrated in Figure 2(i) the first term captures the expected value of the firm from the sum of the equity and debt value to owner $l$ in case the firm does not default. In Figure 2(ii), which shows the marginal distribution of operating fixed costs $h(f)$, the firm is not in the default state for fixed costs below the the product market profit net of debt, $f<\pi(l)-D$. The second term is expected value of the firm in terms of debt value when it defaults but does not close down: $0<\pi(l)-f-B_{l}<D$. The third term shows the expected bankruptcy cost when the firm closes down under default: in this region the reduced-form product market profits do not cover the operating fixed cost $(\pi(l)<f)$. Assuming that the second order condition, $-\tau_{c} H^{\prime}(\cdot)+B_{l} h^{\prime}(\cdot)<0$, is satisfied, the optimal debt level $D^{*}(l)$ is given from:

$$
\underbrace{\left.\tau H\left(\pi(l)-D^{*}(l)\right)\right)}_{M B}=\underbrace{\left.B_{l} h\left(\pi(l)-D^{*}(l)\right)\right)}_{M C} .
$$

This equation illustrates that the marginal benefit of leverage (MB) is the reduced expected corporate tax payments, $\left.\tau H\left(\pi(l)-D^{*}(l)\right)\right)$, whereas the marginal cost (MC) is the increase expected real bankruptcy costs, $\left.B_{l} h\left(\pi(l)-D^{*}(l)\right)\right) .{ }^{8}$ Put differently, a one unit increase in debt gives $\tau$ units in tax reduction for all realizations of $f$ for which the firm does not default. This occurs with probability $\left.H\left(\pi(l)-D^{*}(l)\right)\right)$. At the same time, a one unit increase in debt also increases the probability of bankruptcy with $\left.h\left(\pi(l)-D^{*}(l)\right)\right)$ in which case the firm has to pay a bankruptcy $\operatorname{cost} B_{l}$ from not being able to fully repay debt $D$. Optimal leverage thus balances the marginal expected tax gains from the debt tax shield against the marginal expected bankruptcy costs. Thus, the presence of a debt tax shield is the only reason for positive leverage in the model.

To see how optimal leverage and firm value are affected by changes in the exogenous parameters $\gamma_{l}$ and $B_{l}$, define the reduced-form value of the firm as $\bar{V}(l) \equiv \bar{V}\left(l, D^{*}(l)\right)$. We have the following Lemma.

Lemma 1 Optimal leverage and firm value is increasing in $\gamma_{l}$ and decreasing in $B_{l}: \frac{d D^{*}(l)}{d \gamma_{l}}=$ $\pi_{\gamma_{l}}^{\prime}(l)>0, \frac{d D^{*}(l)}{d B_{l}}=\frac{h(.)}{B_{l} h^{\prime}(.)-\tau h(.)}<0, \frac{d \bar{V}(l)}{d \gamma_{l}}>0$ and $\frac{d \bar{V}(l)}{d B_{l}}<0$.

Optimal leverage increases in productivity $\gamma_{l}$ because $\gamma_{l}$ increases product market profits. At an unchanged leverage, the firm faces a lower bankruptcy risk which enables it to increase

\footnotetext{
${ }^{8}$ To obtain this first order condition, recall that the general Leibniz integral rule states $\frac{d}{d x} \int_{a(x)}^{b(x)} f(y, x) d y=$ $\frac{d b(x)}{d x} f(b(x), x)-\frac{d a(x)}{d x} f(a(x), x)+\int_{a(x)}^{b(x)} \frac{d}{d x} f(y, x) d y$.
} 
its debt level. Optimal leverage decreases in bankruptcy costs $B_{l}$ because the marginal cost of leverage increases when bankruptcy becomes more expensive. To see that total firm value is increasing in $\gamma_{l}$, use of the envelope theorem shows that

$$
\begin{aligned}
\frac{d \bar{V}(l)}{d \gamma_{l}} & =\frac{\partial \bar{V}(l)}{\partial d \gamma_{l}} \\
& =\underbrace{\int_{0}^{\pi(l)-D^{*}(l)}(1-\tau) \pi_{\gamma}^{\prime}(l) h(f) d f}_{\text {Increase in profit when no default }}+\underbrace{\pi_{\gamma}^{\prime} B_{l} h\left(\pi(l)-D^{*}(l)\right)}_{\text {Lower bankruptcy cost from less likely bankruptcy }} \int_{\substack{\pi(l)-D^{*}(l) \\
\text { Increase in profit when default }}}^{\pi(l)} \pi_{\gamma}^{\prime}(l) h(f) d f
\end{aligned}
$$

This expression underscores that the expected value of the firm increases in $\gamma_{l}$ for two reasons. First, reduced product market profits increase in productivity as long as the firm does not close down. Second, by increasing the product market profit, a higher $\gamma_{l}$ also reduces the risk of default and therefore reduces expected bankruptcy costs. We can also use the envelope theorem to show the last part of the lemma:

$$
\frac{d \bar{V}(l)}{d B_{l}}=\frac{\partial \bar{V}(l)}{\partial B_{l}}=-\underbrace{1-H\left(\pi(l)-D^{*}(l)\right)}_{\text {Increase in expected bankruptcy costs }}]_{<.}<0
$$

When $B_{l}$ increases, expected firm value decreases because total expected bankruptcy costs increase. This increase occurs for all states in which the firm cannot repay its debt.

The above arguments presumed that optimal leverage was set to be strictly positive. But because the bankruptcy costs $B_{l}$ are only incurred when debt repayment promises are made, it is plausible that the firm may not want to avoid taxes by using debt because the gain does not justify the risk of incurring bankruptcy costs $B_{l}$. Specifically, we may have $\bar{V}(l) \equiv \bar{V}\left(l, D^{*}(l)\right)>$ $\bar{V}(l, 0)$. From $(5)$, it is possible to show that using debt to lower tax payments is optimal if $B_{l}<\tau \frac{H(\pi(l))-H\left(\pi(l)-D^{*}(l)\right)}{1-H\left(\pi(l)-D^{*}(l)\right)}$. To make the analysis interesting we will, in the remainder of the analysis, assume that this condition holds. It is always fulfilled when the tax rate is sufficiently high and/or the bankruptcy cost $B_{l}$ is not too high.

Note that we here for simplicity have followed the set-up of a standard finance trade-off theory model for capital structure choice (see e.g. Bradley et al. (1983)) where both the interest and principal is tax deductible. In most jurisdictions only the interest would be tax deductible. Changing the set-up to such a setting would complicate the analysis but we conjecture that it would not change our results.

\subsection{Stage 1: The Acquisition Auction}

The acquisition process in stage one is depicted as an auction where owner types $i$ and $p$ simultaneously post bids. Everyone announces a bid, $b_{j}$, which is either accepted or rejected by $t$. Following the announcement of bids, $t$ 's assets are sold to the highest bidder. If there is more than one bidder with a highest bid, each obtains the assets with equal probability. The acquisition is solved for Nash equilibria in undominated pure strategies. There is a smallest amount $\epsilon$ chosen such that all inequalities are preserved if $\epsilon$ is added or subtracted.

To solve the auction and determine bids, we need to determine the valuations of the bidders for obtaining the assets. To aid in this, we introduce the net gain function $\Delta_{l}(S)=v(l)-S$ which defines the net gain for a bidder of type $l$ if the acquisition price is $S$. The maximum willingness to pay for $l$ is $v_{l} \equiv \max S$, s.t $\Delta_{l}(S) \geq 0$. This gives

$$
v_{l}=\bar{V}(l)
$$

Given the valuations $v_{l}$ we can now solve the auction for $t$ 's assets and determine the equilibrium 
ownership structure and acquisition price.

Lemma 2 The equilibrium ownership structure $l^{*}$ and the acquisition price $S^{*}$ are described in Table 1.

\begin{tabular}{cccc}
\hline \hline Ineq: & Definition: & $\begin{array}{c}\text { Equilibrium } \\
\text { owner, } \mathrm{l}^{*}:\end{array}$ & $\begin{array}{c}\text { Acquisition } \\
\text { price, } \mathrm{S}^{*}\end{array}$ \\
\hline$I 1:$ & $v_{p}>v_{i}$ & $p$ & $v_{p}$ \\
$I 2:$ & $v_{i}>v_{p}$ & $i$ & $v_{i}$ \\
\hline \hline
\end{tabular}

Table 1: The equilibrium ownership structure and the acquisition price.

Proof. See the Appendix.

Intuitively, bidding competition ensures that all owner types $i$ bid $v_{i}$ and all owner types $p$ bid $v_{p}$. Lemma 2 then states that the assets end up with the owner that has the highest valuation, equalling total expected firm value, and that this owner pays his or her full valuation.

\section{When Does the Debt Tax Shield Distort Ownership Ef- ficiency?}

Let us now examine if the market solution of allocating ownership of the target firm coincides with the socially efficient ownership. To proceed, we first complement the value of the expected value of the firm $\bar{V}(l)$ with the expected consumer surplus $\bar{C} S(l)$ and the expected tax revenues

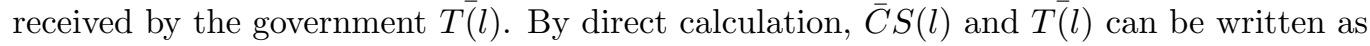

$$
\begin{aligned}
\bar{C} S(l) & =C S(l) H(\pi(l)) \text { and } \\
\bar{T}(l) & =\int_{0}^{\pi(l)-D^{*}(l)} \tau\left[\pi(l)-f-D^{*}(l)\right] h(f) d f .
\end{aligned}
$$

Some further comparative statics results are also useful. First, we have that the expected consumer surplus is strictly increasing in productivity $\gamma_{l}$, while it is unaffected by real bankruptcy costs $B_{l}$. From (10):

$$
\begin{aligned}
& \frac{d \bar{C} S(l)}{d \gamma_{l}}=\frac{d C S(l)}{d \gamma_{l}} \cdot H(\pi(l))+C S(l) \cdot h(\pi(l)) \cdot \pi_{(+)}^{\prime}(l)>0 \text { and } \\
& \frac{d \bar{C} S(l)}{d B_{l}}=0 .
\end{aligned}
$$

Higher productivity increases expected consumer surplus from two effects. First, when the target firm is more efficiently run this will benefit consumers by some combination of lower prices and higher quality as seen in the first term in (12). Second, since productivity also increase the product market profit in the target firm after an acquisition, default is less likely as higher fixed costs can be sustained, increasing the range of fixed costs over which the market is served.

Second, tax revenues are not affected by productivity but are increasing in real bankruptcy costs. From (11) we have

$$
\begin{aligned}
& \frac{d \bar{T}(l)}{d \gamma_{l}}=0 \text { and } \\
& \frac{d \bar{T}(l)}{d B_{l}}=-\tau \frac{d D^{*}(l)}{d B_{l}} H\left(\pi(l)-D^{*}(l)\right)>0 .
\end{aligned}
$$


The intuition for why higher productivity does not affect expected tax revenues can be seen from Lemma 1 where $\frac{d D^{*}(l)}{d \gamma_{l}}=\pi_{\gamma_{l}}^{\prime}(l)$. Thus, any increase in profits stemming from higher productivity results in an equal increase in leverage, leaving expected tax revenues unchanged. The increase in tax revenues as a result of higher real bankruptcy costs can be seen as follows: An increase in the bankruptcy costs reduces optimal leverage from Lemma $1, \frac{d D^{*}(l)}{d B_{l}}<0$. Each dollar of lower leverage then translates into $\tau$ dollars in tax revenues, for all realizations over which the firm pays taxes, which occurs with the cumulative probability $H\left(\pi(l)-D^{*}(l)\right)$.

\subsection{The Socially Efficient Allocation of Assets}

Let us now formally define total welfare under ownership $l$. This is

$$
\bar{W}(l)=\underbrace{\bar{C} S(l)}_{\text {Consumers }}+\underbrace{T \bar{T}(l)}_{\text {Government }}+\underbrace{S^{*}}_{\text {Target }}+\underbrace{\bar{V}(l)-S^{*}}_{\text {Acquirer }},
$$

where $\bar{C} S(l)$ is the expected consumer surplus, $T(\bar{l} l)$ is the expected tax payment received by the government, $S^{*}$ is the surplus accruing the target, and $\bar{V}(l)-S^{*}$ is the surplus of the acquiring firm $l$. The acquirer's surplus, $\bar{V}(l)-S^{*}$, will equal zero in equilibrium because bidding competition drives up prices to $S^{*}=v_{l}=V(l)$. The acquisition price cancels out in equation (16) because it is just a transfer between agents.

Hence, expected welfare $\bar{W}(l)$ can be written as:

$$
\bar{W}(l)=\bar{V}(l)+\bar{C} S(l)+\overline{T(l)} .
$$

We then have the following definition.

Definition 2 Ownership efficiency holds if $l^{*} \equiv \arg \max _{l} \bar{V}(l)=l^{w} \equiv \arg \max _{l} \bar{W}(l)$.

Thus, ownership efficiency $\left(l^{*}=l^{w}\right)$ prevails if the market mechanism in Lemma 2 allocates the target firm to the firm type which gives the highest expected welfare.

\subsection{Ownership Efficiency in the Presence of a Debt Tax Shield}

The debt tax shield gives firms an incentive to take on leverage. Thus, in the absence of a debt tax shield it directly follows that debt will be zero and the owner that makes the most productive use of the assets (has the highest $\gamma$ ) will obtain the assets. In short, ownership efficiency always arises without a tax shield of debt. Let us now examine the conditions under which the market outcome in Lemma 2, which arises under a debt tax shield, achieves ownership efficiency.

Start from a situation where all potential acquirers are symmetric. Then, the two types of firms are identical, with equal bankruptcy $\operatorname{costs} B_{i}=B_{p}$ and equal productivity $\gamma_{i}=\gamma_{p}$, which implies that the two types of firms have identical valuations $v_{i}=\bar{V}(i)=v_{p}=\bar{V}(p)$. Total welfare must be the same under the two types of ownership, $\bar{W}(i)=\bar{W}(p)$. The equilibrium ownership is indeterminate, but (trivially) ownership efficient. Consider now the following comparative statics.

Productivity. Suppose that one type of owner becomes more productive but both owner types are still equal in financial expertise. Since the value of acquiring the target is monotonically increasing productivity from Equation $7, \frac{d \bar{V}(l)}{d \gamma_{l}}>0$, the owner with the highest productivity $(\gamma)$ will then obtain the target firm's assets.

Higher productivity must also unambiguously increase total welfare. This is easily verified from differentiating (17) in $\gamma_{l}$ and using the results in (7), (12) and (14):

$$
\frac{d \bar{W}(l)}{d \gamma_{l}}=\frac{d \bar{V}(l)}{d \gamma_{l}}+\frac{d \bar{C} S(l)}{\begin{array}{c}
d \gamma_{l} \\
(+)
\end{array}}+\frac{d \bar{T}(l)}{\begin{array}{c}
d \gamma_{l} \\
(=0)
\end{array}}>0 .
$$

We thus have the following proposition: 
Proposition 1 Suppose that both owners have equal financial expertise $\left(B_{i}=B_{l}\right)$. Then, ownership efficiency will hold in the presence of a debt tax shield.

Intuitively, if one owner experiences an increase in productivity $\left(\gamma_{l}\right)$, the market will allocate the target firm to this owner. Since both owners are equal in financial expertise, the market allocation is also the socially efficient allocation and ownership efficiency prevails.

Financial expertise. Now assume that both type of owners are equally productive $\left(\gamma_{i}=\gamma_{p}\right)$, but financial expertise deteriorates for one type, that is, the real bankruptcy $\operatorname{cost} B_{l}$ increases for one type. Since the value of acquiring the target is monotonically declining in real bankruptcy costs the assets from Equation $8, \frac{d \bar{V}(l)}{d B_{l}}<0$, the owner type with the lower real bankruptcy cost will then obtain the target.

Will assigning the target to the owner with the lower real bankruptcy cost then lead to a higher expected welfare? Differentiating expected total welfare $\bar{W}(l)$ in $B_{l}$ and using the results in (8), (13) and (15) gives

$$
\begin{aligned}
& \frac{d \bar{W}(l)}{d B_{l}}=\frac{d \bar{V}(l)}{\underset{(-)}{d B_{l}}}+\frac{d \bar{C} S(l)}{\underset{(=0)}{d B_{l}}}+\frac{d \bar{T}(l)}{\underset{(+)}{d B_{l}}} \\
& =-\left[1-H\left(\pi(l)-D^{*}(l)\right)\right]-\tau \cdot \frac{d D^{*}(l)}{d B_{l}} \cdot H\left(\pi(l)-D^{*}(l)\right) .
\end{aligned}
$$

Define $\bar{B}(l)=\left[1-H\left(\pi(l)-D^{*}(l)\right)\right] B_{l}$ as the expected bankruptcy cost. Then, using the firstorder condition (6) to rewrite the second term in (19), we obtain

$$
\begin{aligned}
& \frac{d \bar{W}(l)}{d B_{l}}=\underbrace{-\left[1-H\left(\pi(l)-D^{*}(l)\right)\right]}_{\text {Direct increase in expected bankruptcy costs (direct effect) }}, \\
& -\underbrace{-B_{l} \cdot h\left(\pi(l)-D^{*}(l)\right) \cdot \frac{d D^{*}(l)}{d B_{l}}(-)}_{\text {Reduction in expected bankruptcy costs from lower debt (indirect effect) }}, \\
& =-\frac{d \bar{B}(l)}{d B_{l}} \lesseqgtr 0 .
\end{aligned}
$$

Thus, the effect on total expected welfare from an increase in the real bankruptcy cost, is simply given from its effect on the expected bankruptcy cost, i.e. $\frac{d \bar{W}(l)}{d B_{l}}=-\frac{d \bar{B}(l)}{d B_{l}}$. In (20), the first term then captures the direct increase in expected bankruptcy costs, which is simply the probability of default. The second term, captures the indirect reduction in expected bankruptcy costs that occurs from lower optimal debt as a result of higher $B_{l}$. Since these effects are of opposite signs, we cannot a priory sign how the expected bankruptcy cost - and, hence, how expected welfare $\bar{W}(l)$-will change from an increase in the real bankruptcy cost $B_{l}$.

The ambiguity in sign of $\frac{d \bar{W}(l)}{d B_{l}}$ in (21) thus stems from the balance of a negative direct cost effect and a positive indirect effect (arising from lower debt). In contrast, (8) shows that firm value $\bar{V}(l)$ is only affected by the negative direct cost effect (the indirect effect from a change in debt has only has a second-order effect from the envelope theorem). Hence, expected firm value unambiguously declines in real bankruptcy $\operatorname{costs}, \frac{d \bar{V}(l)}{d B_{l}}<0$.

Now, if the positive indirect effect from lower debt dominates the negative direct cost effect in (20), expected bankruptcy costs decline in real bankruptcy costs, $\frac{d \bar{B}(l)}{d B_{l}}<0$, which from (21) implies $\frac{d \bar{W}(l)}{d B_{l}}=-\frac{d \bar{B}(l)}{d B_{l}}>0>\frac{d \bar{V}(l)}{d B_{l}}$. Social and private incentives are then misaligned: while the socially optimal owner is the type with lower financial expertise (i.e. an owner with a higher real bankruptcy cost, $B_{l}$ ), the market will always assign the target to the owner with better financial expertise (i.e. an owner with a lower real bankruptcy cost, $B_{l}$ ). As we show in Appendix A.2, this occurs because the tax savings from higher leverage will then outweigh the 
higher expected bankruptcy costs. In sum, firms use leverage to minimize the tax burden. This has negative effects on social welfare only when the use of leverage to minimize the tax burden is also accompanied by an increase in expected bankruptcy costs.

Proposition 2 Suppose that both owners are equally productive $\left(\gamma_{i}=\gamma_{p}\right)$. Then, ownership efficiency will hold in the presence of a debt tax shield if expected bankruptcy costs are increasing in real bankruptcy costs: $\frac{d \bar{B}}{d B_{l}}>0$. That is if

$$
\underbrace{1-H\left(\pi(l)-D^{*}(l)\right)}_{\text {Direct effect }}>\underbrace{-B_{l} \cdot h\left(\pi(l)-D^{*}(l)\right) \cdot \frac{d D^{*}(l)}{d B_{l}}}_{\text {Indirect effect }} .
$$

Under Proposition 2 the market is ownership efficient: it will allocate the target firm to the owner with better financial expertise (i.e. the owner with the lower real bankruptcy cost $B_{l}$ ) and this will lead to a higher expected welfare. Ownership efficiency holds when the expected bankruptcy costs increase in real bankruptcy cost, $\frac{d \bar{B}(l)}{d B_{l}}>0$.

To obtain an intuition for when this is likely to hold, note that it will hold when the direct effect dominates the indirect effect in (22). Since the direct effect is simply the probability of default, ownership efficiency is more likely to hold when the firm takes on more debt. Now, since the only reason for firms to be leveraged in this model is the debt tax shield, we would predict that ownership efficiency will hold when the firm is subject to a high tax rate, $\tau$. This - somewhat counter-intuitive result - can be illustrated making use of the uniform distribution: ${ }^{9}$

Corollary 1 Suppose that the probability density function $h(f)$ is uniformly distributed over its support $\left[0, f^{\max }\right]$. Then, ownership efficiency will hold in the presence of a debt tax shield if the tax rate is sufficiently high, $\tau>2 \frac{B_{l}}{f^{\max }}$.

Summing up, firms use leverage to minimize the tax burden. This has negative effects on welfare only when the use of leverage to minimize the tax burden - in combination with better financial expertise - is accompanied by an increase in expected bankruptcy costs. Better financial expertise then drives up the value of an acquisition as the expected tax reduction from higher leverage dominates higher expected bankruptcy costs. If on the other hand, better financial expertise leads to decrease in the expected bankruptcy cost, social and private interests are aligned.

Let us end with a remark on the situation when financial expertise $\left(B_{l}\right)$ can substitute for productivity $\left(\gamma_{l}\right)$. Again assume that productivity and financial expertise are initially the same for the two types. Suppose that we increase financial expertise for one type (i.e. $d B_{l}<0$ ) while simultaneously decreasing productivity of this type $\left(d \gamma_{l}<0\right)$, but in such a way that firm value still increases:

$$
d \bar{V}(l)=\underbrace{\frac{d \bar{V}(l)}{d B_{l}}}_{-} \cdot d B_{l}+\underbrace{\frac{d \bar{V}(l)}{d \gamma_{l}}}_{+} \cdot d \gamma_{l}>0 .
$$

where we have used (7) and (8). Then, we know that the market from Lemma 2 will allocate the target to the the firm with better financial expertise (the owner with lower $B_{l}$ ). Furthermore, suppose that the expected bankruptcy costs decrease in real bankruptcy cost, i.e. $\frac{d \bar{W}(l)}{d B_{l}}=$ $-\frac{d \bar{B}(l)}{d B_{l}}>0$ (Condition 22 does not hold). Then:

$$
d \bar{W}(l)=\underbrace{\frac{d \bar{W}(l)}{d B_{l}}}_{+} \cdot d B_{l}+\underbrace{\frac{d \bar{W}(l)}{d \gamma_{l}}}_{+} \cdot d \gamma_{l}<0 .
$$

\footnotetext{
${ }^{9}$ Under reasonable conditions, a higher tax rate leads to increased debt. Differentiating (6) in $\tau$ and $D$, we get $\frac{d D^{*}(l)}{d \tau}=\frac{\tau \cdot h\left(\pi(l)-D^{*}(l)\right)-B_{l} \cdot h^{\prime}\left(\pi(l)-D^{*}(l)\right)}{H\left(\pi(l)-D^{*}(l)\right)}$. Given that $h^{\prime}\left(\pi(l)-D^{*}(l)\right)$ is small in absolute value, this ensures $\frac{d D^{*}(l)}{d \tau}>0$. This result holds with the uniform distribution since $h(f)=1 / f^{\max }$.
} 
where we have used (18). Thus, when the market allocates the target to the owner with the higher financial expertise but lower productivity we have two negative effects on expected welfare. First, expected welfare declines as expected bankruptcy costs increase. Second, expected welfare declines because productivity is reduced. ${ }^{10}$

\section{Concluding Remarks}

We develop a model for studying how the debt tax shield affects the ownership of corporate assets in the market for corporate control when bidders differ in terms of how productively they can make use of the corporate assets and in terms of their costs in case bankruptcy occurs.

We find that the debt tax shield need not always distort the ownership allocation of corporate assets. Assets end up with the socially preferred owner when differences in financial and productive expertise between bidders is small and better financial expertise reduces expected bankruptcy costs.

As regards to future research, our framework omits, but can be extended to include, differences in capital gains and divided taxation, inter-temporal effects of tax payments, tax loss carry forwards, internal transfer policies for incumbent firms, dividend policy decisions and differences between asset and share acquisitions. Additionally, it is well suited to incorporate limited product market competition among incumbent firms and a richer financial contracting environment that goes beyond equity and debt contracts.

\footnotetext{
${ }^{10}$ See Appendix A.3 for details.
} 


\section{References}

Almazan, A., A. de Motta, and S. Titman. 2012. Debt, labor markets and the creation and destruction of firms. Mimeo.

Axelson, Ulf, Tim Jenkinson, Per Strömberg, and Michael S. Weisbach. 2013. Borrow cheap, buy high? The determinants of leverage and pricing in buyouts. Journal of Finance 68, 2223-2267.

Badertscher, Brad, Sharon P. Katz, and Sonja Olhoft Rego. 2009. The impact of private equity ownership on corporate tax avoidance. HBS Working Paper 10-004.

Banal-Estanol, Albert and Marco Ottaviani. 2006. Mergers with product market risk. Journal of Economics 83 Management Strategy 15, 577-608.

Becker, Johannes and Clemens Fuest. 2009. Source versus residence based taxation with international mergers and acquisitions. CESIFO Working Paper No 2854.

Becker, Johannes and Clemens Fuest. 2010. Taxing foreign profits with international mergers and acquisitions. International Economic Review 51, 171-186.

Becker, Johannes and Clemens Fuest. 2011. Tax competition - greenfield investment versus mergers and acquisitions. Regional Science and Urban Economics 41, 476-486. CESifo Working Paper No 2247.

Bradley, Michael, Gregg A. Jarrell, and E. Han Kim. 1983. On the existence of an optimal capital structure: Theory and evidence. Journal of Finance 39, 857-878.

Brander, James A. and Tracy R. Lewis. 1986. Oligopoly and financial structure: The limited liability effect. American Economic Review 76, 956-970.

Brander, James A. and Tracy R. Lewis. 1988. Bankruptcy costs and the theory of oligopoly. Canadian Journal of Economics 21, 221-243.

Cestone, Giacinta and Chiara Fumagalli. 2005. The strategic impact of resource flexibility in business groups. RAND Journal of Economics 36, 193-214.

Chang, Ya-Kai, Yu-Lun Chen, Robin K. Chou, and Tai-Hsin Huang. 2015. Corporate governance, product market competition and dynamic capital structure. International Review of Economics \&3 Finance 38, 44-55.

de Mooij, Ruud A. 2011. Tax biases to debt finance: Assessing the problem, finding solutions. Fiscal Studies 33, 489-512.

Desai, Mihir A. and James R. Hines. 2004. Rules and new realities: Corporate tax policy in a global setting. National Tax Journal 57, 937.

Devereux, Michael. 2008. Taxation of outbound direct investment: Economic principles and tax policy considerations. Oxford University Centre for Business Taxation Working Paper 0824.

Egger, P, W Eggert, C Keuschnigg, and H Winner. 2010. Corporate taxation, debt financing and foreign-plant ownership. European Economic Review 54, 96-107.

Gordon, Roger H. and Ary Lans Bovenberg. 1996. Why is capital so immobile internationally? Possible explanations and implications for capital income taxation. American Economic Review 86, 1057-1075.

Graham, John R. 2006. A review of taxes and corporate finance. Foundations and Trends in Finance 1, 573-691.

Haufler, Andreas and Marco Runkel. 2012. Firms' financial choices and thin capitalization rules under corporate tax competition. European Economic Review 56, 1087-1103. 
Haufler, Andreas and Christian Schulte. 2007. Merger policy and tax competition. Discussion Papers in Economics 2074, University of Munich.

He, Z. and G Matvos. 2012. Debt and creative destruction: Why could subsidizing corporate debt be optimal? Mimeo.

Hotchkiss, Edith S., David C. Smith, and Per Strömberg. 2011. Private equity and the resolution of financial distress. Available at SSRN: http://ssrn.com/abstract=1787446.

Jenkinson, Tim and Rüdiger Stucke. 2011. Who benefits from the leverage in LBOs? Available at SSRN: http://ssrn.com/abstract=1777266.

Jensen, Michael C. and William H. Meckling. 1976. Theory of the firm: Managerial behavior, agency costs and ownership structure. Journal of Financial Economics 3, 305-360.

Kaplan, Steven N. 1989. Management buyouts: Evidence on taxes as a source of value. Journal of Finance 44, 611-632.

Kemsley, Deen and Doron Nissim. 2002. Valuation of the debt tax shield. Journal of Finance 57, $2045-2074$

Kiyotaki, Nobuhiro and John Moore. 1997. Credit cycles. Journal of Political Economy 105, 211-248.

Leland, Hayne E. 2007. Financial synergies and the optimal scope of the firm: Implications for mergers, spinoffs, and structured finance. Journal of Finance 62, 765-807.

Myers, Stewart. 1990. Determinants of corporate borrowing. Journal of Financial Economics 5, $147-175$

Norbäck, Pehr-Johan, Lars Persson, and Joacim Tåg. 2013. Buying to sell: Private equity buyouts and industrial restructuring. CEPR Discussion Paper No 8992.

Norbäck, Pehr-Johan, Lars Persson, and Jonas Vlachos. 2009. Cross-border acquisitions and taxes: Efficiency and tax revenues. Canadian Journal of Economics 42, 1473-1500.

Schindler, Dirk and Guttorm Schjelderup. 2012. Debt shifting and ownership structure. European Economic Review 56, 635-647.

Shleifer, Andrei and Robert W. Vishny. 1992. Liquidation values and debt capacity: A market equilibrium approach. Journal of Finance 47, 1324-1366. 


\section{APPENDIX}

\section{A Proofs}

\section{A.1 Proof of Lemma 2}

Note that $b_{j} \geq \max v_{l}$ for $l=\{i, p\}$ is a weakly dominated strategy, since no owner will post a bid equal to or above its maximum valuation of obtaining the assets and $t$ will accept a bid iff $b_{j}>0$. Then, competition within owner groups means that the equilibrium acquisition price must be $v_{i}-\epsilon$ and $v_{p}-\epsilon$ for $i$ and $p$ respectively (any $j$ deviating to a bid $v_{l}-2 \epsilon$ will post a losing bid and prefer to bid his or her maximum valuation instead). It then follows that an owner of type $p$ acquires the assets at price $v_{p}-\epsilon$ iff $v_{p}>v_{i}$ and that $i$ acquires the assets at price $v_{i}-\epsilon$ iff $v_{i}>v_{p}$. To simplify, we ignore $\epsilon$ in the equilibrium acquisition prices for the remainder of the paper.

\section{A.2 Bankruptcy costs and the envelope theorem}

Suppose that private and social incentives are not aligned so the market solution will not produce ownership efficiency. This holds when

$$
\frac{d \bar{W}(l)}{d B_{l}}=-\frac{d \bar{B}(l)}{d B_{l}}>0>\frac{d \bar{V}(l)}{d B_{l}} .
$$

To proceed, define the expected profit net of taxes and bankruptcy costs:

$$
\bar{\Pi}(l)=\int_{0}^{\pi(l)}[\pi(l)-f] h(f) d f .
$$

Using (26), the expected value of the firm $\bar{V}(l)$ can then be written as

$$
\bar{V}(l)=\bar{\Pi}(l)-\bar{B}(l)-\bar{T}(l) .
$$

Differentiating (27) in $B_{l}$ we have

$$
\frac{d \bar{V}(l)}{d B_{l}}=\underbrace{-\frac{d \bar{B}(l)}{d B_{l}}}_{\text {Increase in value from lower } \bar{B}(l)} \quad \underbrace{-\frac{d \bar{T}(l)}{d B_{l}}}_{\text {Decrease in value from higher } \bar{T}(l)}<0
$$

where the fall in expected bankruptcy $\operatorname{cost} \frac{d \bar{B}(l)}{d B_{l}}<0$ is implied by (25), the increase in tax payments $\frac{d \bar{T}(l)}{d B_{l}}>0$ stems from (15), and fall in firm value $\frac{d \bar{V}(l)}{d B_{l}}<0$ is derived in (8).

Now, if firm value $\bar{V}(l)$ falls when real bankruptcy cost $B_{l}$ increase, the increase in firm value generated by the reduction in expected bankruptcy costs $\left(-\frac{d \bar{B}(l)}{d B_{l}}>0\right)$ must be smaller than the reduction in firm value generated by the increase in tax payments $\left(\frac{d \bar{T}(l)}{d B_{l}}>0\right)$. But then it follows that firm value $\bar{V}(l)$ must increases in response to a reduction in real bankruptcy cost, $B_{l}$. The associated decline in firm value from higher expected bankruptcy cost must then be smaller than the associated increase in firm value from lower tax payments. Formally:

$$
\frac{d \bar{V}(l)}{d B_{l}} \cdot d B_{l}=\underbrace{-\frac{d \bar{B}(l)}{d B_{l}} \cdot d B_{l}}_{\text {Decrease from higher exp bankruptcy costs }}(\begin{array}{l}
\text { Increase from lower exp. tax payments } \\
(-)
\end{array} \quad \underbrace{-\frac{d \bar{T}(l)}{d B_{l}} \cdot d B_{l}(-)}_{(+)}(+)
$$


On a final note, we can also use (28) and (15) to verify (8):

$$
\begin{aligned}
\frac{d \bar{V}(l)}{d B_{l}}= & \underbrace{-\frac{d \bar{B}(l)}{d B_{l}}}_{\text {Increase in value from lower } \bar{B}(l) \quad \text { Decrease in value from higher } \bar{T}(l)} \\
= & -\left[1-H\left(\pi(l)-D^{*}(l)\right)\right]-B_{l} \cdot h\left(\pi(l)-D^{*}(l)\right) \cdot \frac{d D^{*}(l)}{d B_{l}} \\
& -\left[\begin{array}{c}
\frac{d \bar{T}(l)}{d B_{l}} \\
-\tau \frac{d D^{*}(l)}{d B_{l}} H\left(\pi(l)-D^{*}(l)\right)
\end{array}\right] \\
(-) & -\left[1-H\left(\pi(l)-D^{*}(l)\right)\right],
\end{aligned}
$$

where we have used (6) for the final step.

\section{A.3 Expression (24)}

Note that when (23) and (24) holds we can rewrite (24), remembering that $d B_{l}<0$ and $d \gamma_{l}<0$, as follows:

$$
\begin{gathered}
d \bar{W}(l)=\underbrace{\underbrace{\frac{d \bar{V}(l)}{d B_{l}}}_{d \bar{V}(l)>0} \cdot d B_{l}+\underbrace{\frac{d \bar{V}(l)}{d \gamma_{l}}}_{+} \cdot d \gamma_{l}}_{-}+ \\
\underbrace{\frac{d \bar{C} S(l)}{d B_{l}} \cdot d B_{l}+\underbrace{\frac{d \bar{C} S(l)}{d \gamma_{l}}}_{+} \cdot d \gamma_{l}}_{=0}+ \\
\underbrace{\frac{d \bar{T}(l)}{d B_{l}} \cdot d B_{l}+\underbrace{\frac{d \bar{T}(l)}{d \gamma_{l}}}_{+} \cdot d \gamma_{l}}_{d \bar{C} S(l)<0} \\
\underbrace{<0}_{d \overline{+}(l)<0}
\end{gathered}
$$

where we have used (12)-(15). From (31), it thus follows that if $d \bar{W}(l)<0$ and $d \bar{V}(l)>0$, we have that $d \bar{C} S(l)<0$ and $d \bar{T}(l)<0$. That is the reduction in expected welfare is associated with lower expected consumer surplus and lower expected tax payments. 